\title{
Oral Cancer Senario in Multiple Centers of Dhaka,
}

\section{Bangladesh}

\author{
Dr. Rajesh Sah ${ }^{1}$, Dr. Mahmuda Akhter ${ }^{* 2}$ \\ ${ }^{1}$ Oral and Maxillofacial Surgery Department, Bangabandhu Sheikh Mujib Medical University, Dhaka, Bangladesh \\ ${ }^{2}$ Oral and Maxillofacial Surgery Department, Bangabandhu Sheikh Mujib Medical University, Dhaka, Bangladesh
}

*Correspondence: Mahmuda Akhter; mahmudanaz@gmail.com

Received: 20 November 2020;

Accepted: 27 November 2020;

Published: 30 November 2020

\begin{abstract}
Oral cancer is one of the common cancers worldwide and in Bangladesh around 7000 cases are diagnosed yearly. It has variable demographics and patient comes to hospital with different presentations. It is mandatory to know the characteristics of the disease so that better awareness and different treatment modalities can be planned. 162 patients with histopathological diagnosis of oral cancer was include in study by consecutive sampling and characteristics of disease was recorded in scientific data collection sheet which was later analyzed by SPSS and result was presented in table, graph and chart form. Incidence of oral cancer is $56.2 \%$ in female, in $59.9 \%$ cases buccal mucosa is involved in which $90.1 \%$ is squamous cell carcinoma. In Conclusion squamous cell carcinoma is most common oral cancer mainly occurs in buccal mucosa of female, in grade I and stage iii majority of patient present in tertiary centers of Dhaka.
\end{abstract}

Keywords: oral cancer, Bangladesh, squamous cell carcinoma

\section{Introduction}

Oral cancer includes cancers of the lips, tongue, oral cavity, oropharynx, hypopharynx and pyriform sinus ${ }^{[1]}$. Oral cancer is the 6th most common cancer worldwide ${ }^{[2]}$. More than 50000 people are diagnosed globally each year and about 30000 mortality annually ${ }^{[3]}$. The highest prevalence was seen among south Asian population $^{[4]}$.

Approximately $85 \%$ to $95 \%$ of all oral cancer is squamous cell carcinoma (SCC). However, multiple other malignant lesions can be found in the oral cavity such as sarcoma, minor salivary gland tumors, mucosal melanoma, lymphoma, or metastatic disease from nearly any site in the body ${ }^{[4]}$.

In Bangladesh, more than 7000 new cases are diagnosed per year with mortality is about $6.6 \%{ }^{[5]}$. Cancer is the sixth leading cause of death in Bangladesh (BBS, 2004), according to the Bangladesh Bureau of Statistics. International Agency for Research on cancer (IARC) stated that cancer related death in Bangladesh is $7.5 \%$ in 2005 and projected to $13 \%$ in 2030 . The prevalence of oral cancer in Bangladesh is second and third leading cancer among males and females respectively ${ }^{[6]}$. Elderly population aged more than 50 years are commonly affected ${ }^{[7]}$. However, the incidence of oral cancer is increasing mostly among young female population at age less than 45 years ${ }^{[8]}$.

The etiology of oral cancer is multifactorial and smoking with alcohol consumption lead the position among established risk factors. Others established risk factors include tobacco chewing, snuff dipping, betel quid with tobacco like products, exposure to sunlight and radiation, viruses (human papilloma virus and Epstein bar virus), immune deficiency, dentition and ethnicity ${ }^{[9]}$. The TNM system devised by the AJCC is designed to stratify cancer patients into different stages based on the characteristics of the primary tumor $\mathrm{T}$ represents size of cancer, $\mathrm{N}$ represents lymph node involvement and metastasis is represented by $\mathrm{M}$.

As of recent situation of reporting high number of patients with oral cancer as mentioned above, a study was needed to carry out in Bangladesh. In Bangladesh, as medical facilities centered around Dhaka are involved in treatment of oral cancer, we can utilize our expertise to know the factors and co-factors related to oral cancer which might lead to develop awareness among the people and make treatment policies in local and national level in sequence to international scenario.

\section{Material and methods}

This was descriptive type of cross-sectional study. 162 patients with histopathologicaliy diagnosed oral cancer, from August 2018 to September 2019, attending in outdoor clinic of Department of Oral and Maxillofacial of following 5 tertiary centers in Dhaka:

1. Bangabandhu Sheikh Mujib Medical University (BSMMU)

2. Dhaka Medical College Hospital (DMCH)

3. Sir Sallimullah Medical College and Mitford hospital (SSMC) 
4. National Institute of Cancer Research and Hospital (NICRH)

5. Dhaka Dental College Hospital (DDCH).

Consecutive sampling technique was used and patient those were already operated for oral cancer, underwent radio/chemo therapy. Cases with recurrent / metastatic cancer and who failed to submit sufficient history were excluded. Objectives of the study were to identify current demographics of oral cancer with risk factors, site, clinical and histopathological types, grades and stages. The informed written consent was taken. Standardized data collection sheet was used to collect the data. Collected data was summarized and analyzed by Statistical Package for the Social Sciences (SPSS) Version 24.0 and results were presented in table, chart and graph form.

\section{Results}

The study was carried out in 162 patients of which $91(56.2 \%)$ were female and $71(43.3 \%)$ were male. The most common site was buccal mucosa 97(59.9\%). Other characteristics are presented in table 1 .

Table 1: General characteristics of patient

\begin{tabular}{|l|l|l|}
\hline Characteristics & & N (\%) \\
\hline \multirow{5}{*}{ Gender } & Male & $\mathbf{9 1}(56.2)$ \\
& Female & $\mathbf{7 1}(43.3)$ \\
\hline & Lowe alveolus & $17(10.5)$ \\
& Buccal mucosa & $97(59.9)$ \\
& Gingivobuccal sulcus & $25(15.4)$ \\
& Lip and palate & $\mathbf{5 ( 3 . 1 )}$ \\
& Tongue & $\mathbf{1 1 ( 6 . 8 )}$ \\
& Retromolar area & $21(13)$ \\
& Others & $\mathbf{2 6}(16)$ \\
\hline
\end{tabular}

The highest number of oral cancer patients recorded at Bangabandhu Sheikh Mujib Medical University were 53 (32.7\%) followed by Dhaka dental college and others as shown in figure 1 .

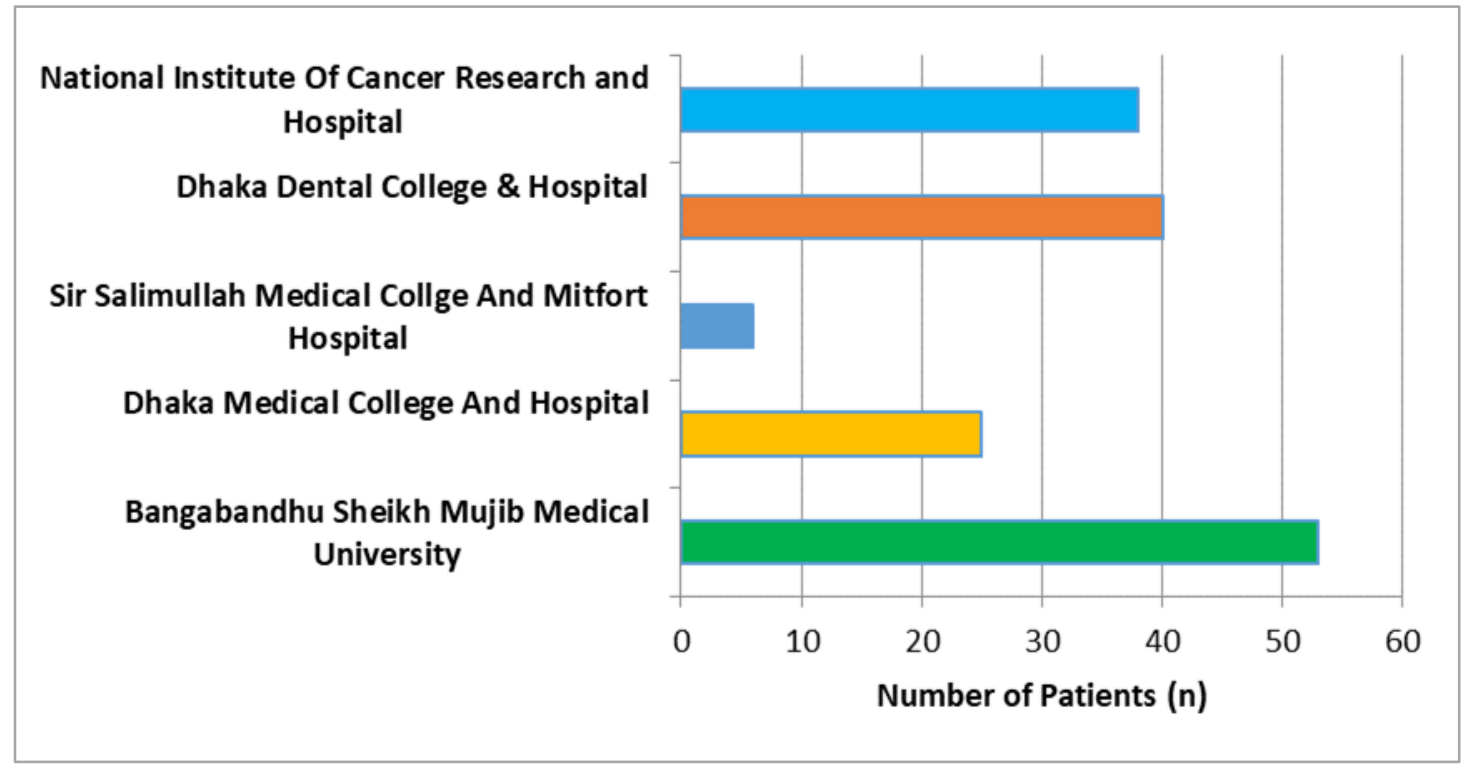

Figure 1: Number of patients included in the study

The most common oral cancer reported was squamous cell carcinomas (SCC) which constituted $(146,90.1 \%)$ followed by Verrucous Carcinomas (4, 2.5\%), Adenoid cystic Carcinomas (3, $1.9 \%)$, Melanomas (3, 1.9\%), Mucoepidermoid Carcinomas (3, $1.9 \%)$, Basal cell carcinoma (1, 0.6\%), Adenocarcinoma (1, 0.6\%) and spindle cell carcinoma $(1,0.6 \%)$, shown in table 2 .

Table 2: Type of cancers

\begin{tabular}{|l|c|c|}
\hline \multirow{2}{*}{ Histological Type } & \multicolumn{2}{|c|}{ N=162 } \\
\cline { 2 - 3 } & $\mathbf{N}$ & $\mathbf{\%}$ \\
\hline SCC & 146 & 90.1 \\
\hline Verrucous Ca. & 4 & 2.5 \\
\hline BCC & 1 & 0.6 \\
\hline Adenoid Cystic Ca. & 3 & 1.9 \\
\hline Melanoma & 3 & 1.9 \\
\hline Mucoepidermoid Carcinoma & 3 & 1.9 \\
\hline Adenocarcinoma & 1 & 0.6 \\
\hline Spindle Cell Carcinoma & 1 & 0.6 \\
\hline
\end{tabular}

Among Oral squamous cell carcinoma cases, the highest numbers patients had Grade I $(99,61.1 \%)$ and stage III malignancies as shown in table 3 .
Table 3: Grading and staging of carcinomas of the study population

\begin{tabular}{|l|l|l|}
\hline Characteristics & & N $(\%)$ \\
\hline \multirow{4}{*}{ Grade } & Grade I & $\mathbf{9 9}(61.1)$ \\
& Grade II & $45(27.8)$ \\
& Grade III & $1(0.6)$ \\
& Grade IV & $1(0.6)$ \\
\hline & Stage I & $\mathbf{8 ( 4 . 9 )}$ \\
& Stage II & $\mathbf{2 4}(14.8)$ \\
& Stage III & $\mathbf{6 6}(40.7)$ \\
& Stage IV A & $43(26.5)$ \\
& Stage IV B & $4(2.5)$ \\
& Stage IV C & $1(0.6)$ \\
\hline
\end{tabular}

\section{Discussion}

This prospective observational study was conducted in five major tertiary centers at Dhaka. Histologically confirmed 162 oral cancer patients from January 2019 to September 2019 were included in the study.

Among the patient's females- 91 (56.2\%) were more than males- $71(43.3 \%)$. Similar results were observed in the study conducted by Adhikari at el. ${ }^{[10]}$ in which they found females were 
$31(53.4 \%)$ and males were $27(46.6 \%)$. Our study shows the most common site of oral cancer was buccal mucosa 97(59.9\%). Similarly, studies by Rahman et al ${ }^{[11]}$ and Habib et al. ${ }^{[12]}$ found buccal mucosa commonly affected in Bangladeshi population, which may be due to habit of high intake of tobacco and betel products. Also, due to the habit of retaining the tobacco and betel ingredients on the buccal sulcus are highly responsible for the development of the carcinomas.

All tertiary hospitals have participated in treatment of oral cancer and other such centers need further improvements along with the peripheral centers to provide better health services.

In this study, the most common oral cancer was squamous cell carcinoma which constituted $(146,90.1 \%)$ and followed by Verrucous Carcinoma (4, 2.5\%), Adenoid cystic Carcinoma (3, $1.9 \%$ ), Melanoma (3, 1.9\%), Mucoepidermoid Carcinoma (3, $1.9 \%)$, Basal cell carcinoma (1, 0.6\%), Adenocarcinoma (1, 0.6\%) and spindle cell carcinoma (1,0.6\%). Similar range of result was observed in the study conducted by Anis and Gaballah ${ }^{[13]}$, in which they found the highest number of oral cancer patients were squamous cell carcinoma (70\%), Mucoepidermoid carcinoma (5.4\%), Adenoid cystic carcinoma (2.7\%), Adenocarcinoma (2.7\%), Spindle cell carcinoma (1.4\%), Malignant melanoma $(1.4 \%)$ and some others. In the year 2018, Dhanuthai at el. ${ }^{[14]}$, study showed similar type of result in which they found squamous cell carcinoma were (80.05\%), Verrucous carcinoma (3.41\%), Mucoepidermoid carcinoma (3.02\%), Adenocystic carcinoma (1.9\%), Adenocarcinoma (1.07\%), Melenoma $(0.60 \%)$, Spindle cell carcinoma $(0.15 \%)$ followed by others.

In the current study, the highest number of patients had Stage III $(66,40.7 \%)$ followed by Stage IVA $(43,26.5 \%)$, Stage II $(24,14.8 \%)$, Stage I $(8,4.9 \%)$, Stage IVB $(4,2.5 \%)$ and Stage IVC $(1, .6 \%)$ in descending order respectively. In 2014, Thomas, Stedman and Davies ${ }^{[15]}$ conducted study in which they observed result of staging of squamous cell carcinoma were very similar, maximum SCC patients were in Stage I (29\%) followed by Stage IV (26\%), Stage II (15\%), Stage III (14\%) and unknown (16\%). In 2018, Sharma, Kim and Paeng ${ }^{[16]}$ did study in which they found highest number of SCC patients had Stage I (44.73\%), followed by Stage II (5.26\%), Stage III (22.36\%) and Stage IVA were (23.68\%) and stage IVB (3.94\%).

In the study the highest number of participants were SCC patients and their histological pattern had Grade I (61.1\%) followed by Grade II $(27.8 \%)$, Grade III $(0.6 \%)$ and Grade IV $(0.6 \%)$. In 2013, Adhikari at el. ${ }^{[10]}$, conducted study in which they also found similar result in histological pattern had Grade I (60.3\%), Grade II $(328 \%)$ and Grade III $(6.9 \%)$. Similar result was seen in Rai and Ahmed ${ }^{[17]}$ Study in which Grade I was (50.8\%), Grade II (29.2\%), Grade III (20\%) and Grade IV not noted.

\section{Conclusion}

In Bangladeshi, squamous cell carcinoma is most common malignancy of oral cavity and its incidence is more in female and buccal mucosa is most common site of occurrence. Among tertiary centers of Dhaka most of the case of oral cancer are reported in department of oral and maxillofacial surgery of Bangabandhu sheikh mujib medical university. And among all reported case majority of patient presented with Grade I and Stage III squamous cell carcinoma of oral cavity.

\section{Ethical Issue}

Ethical clearances and permissions were taken from institutional review board of BSMMU and permission for study was taken from all five tertiary centers.

\section{Conflict of Interest}

The authors declare no conflict of interest.

\section{References}

[1] Avon S, and Klieb H. Oral Soft-Tissue Biopsy. Journal of Canadian Dental Association. 2012 July;78:c75.

[2] Christopher M. Harris and G. E. Ghali. Oral cancer; Etiology, Diagnosis, Classification and Staging. In: M. Miloro, G. Ghali, P. Larsen and p. Waite, ed., Principles of Oral and Maxillofacial Surgery. 3rd ed.2012.

[3] Hussein A, Helder M, de Visscher J, Leemans C, Braakhuis B, de Vet H. and Forouzanfar T. Global incidence of oral and oropharynx cancer in patients younger than 45 years versus older patients: A systematic review. European Journal of Cancer. 2017; 82:115-127.

[4] Hussain, S. Comprehensive update on cancer scenario of Bangladesh. South Asian Journal of Cancer.2013; 2(4): 279-284.

[5] Sultana N, Malik M. The Overview of Oral Cancer and Risk Factors in Bangladesh. International Journal of Dental Science \& Research .2014;2(5A):8-10.

[6] Hussain SA, Sullivan R. Cancer Control in Bangladesh. Japanese Journal of Clinical Oncology.2013;43(12):1159-1169.

[7] Tandon P, Dadhich A, Saluja H, Bawane S, Sachdeva S. The Prevalence of Squamous cell carcinoma in Different sites of oral cavity at our Rural health Care Centre in Loni, Maharashtra- a retrospective 10-years study. Contemporary Oncology.2017;21(2):178-173.

[8] Saba NF, Goodman M, Ward K, Flowers C, Ramalingam S. Owonikoko T, Chen A, Grist W, Wadsworth T, Beitler J J, Khuri F R, and Shin D M. Gender and Ethnic Disparities in Incidence and Survival of Squamous Cell Carcinoma of the Oral Tongue, Base of Tongue, and Tonsils: A Surveillance, Epidemiology and End Results Program-Based Analysis. Oncology.2011; 81: 12-20.

[9] Sultana N, and Malik M. The Overview of Oral Cancer and Risk Factors in Bangladesh. International Journal of Dental Sciences and Research. 2014;2(5A): 8-10.

[10] Adhikari RB, Karmacharaya A, Malla N, and Gurung MN. Oral Squamous cell Carcinoma Pattern in Manipal Teaching Hospital, Nepal. American Journal of Public Health Research.2015; 3(5): 41-43.

[11] Rahman QB, Gautam S, Habib MA. A Study to Detect Sentinel Lymph Node by Methylene Blue Dye and Histopathological Confirmation of Metastasis in Oral Squamous Cell Carcinoma Patient. American Journal of Oral and Maxillofacial Surgery.2018; 5(1): 13-21.

[12] Habib MA, Rahman QB, Imon AA, Kundu GC. Effectiveness of Preoperative lymphoscintigraphy for the detection of cervical lymph node metastasis in patient with oral squamous cell carcinoma. Ann Maxillofac Surg.2017; 7(1): 30-36.

[13] Anis R, and Gaballah K. Oral cancer in the UAE: a multicenter, retrospective study. Libyan Journal of Medicine. 2013;8: 10.3402/ljm. v8i0. 21782. 
[14] Dhanuthai K, Rojanawatsirivej S, Thosaporn W, Kintarak S, Subarnbhesaj A, Darling M, Kryshtalskyj E, Chiang C, Shin H, Choi S, Lee S, and Shakib P. Oral cancer: A multicenter study. Medicina Oral Patología Oral y Cirugia Bucal. 2018; 23(1): e23-e29.

[15] Thomas B, Stedman M, and Davies L. Grade as a prognostic factor in oral squamous cell carcinoma: A population-based analysis of the data. Laryngoscope.2014; 124(3), 688-694.
[16] Sharma A, Kim J, and Paeng J. Clinical analysis of neck node metastasis in oral cavity cancer. Journal of the Korean Association of Oral and Maxillofacial Surgeons. 2018; 44(6): 282-288.

[17] Rai H, and Ahmed J. Clinicopathological Correlation Study of Oral Squamous Cell Carcinoma in a Local Indian Population. Asian Pacific Journal of Cancer Prevention.2016; 17(3): 1251-1254. 